\title{
Theoretical Study of the Stacking Behavior of Selected Polycondensed Aromatic Hydrocarbons with Various Symmetries
}

\author{
Jens Antony, ${ }^{\dagger}$ Bassam Alameddine, ${ }^{\ddagger}$ Titus A. Jenny, ${ }^{\S}$ and Stefan Grimme ${ }^{\dagger} *$ \\ ${ }^{\dagger}$ Mulliken Center for Theoretical Chemistry, University of Bonn, Beringstraße 4, 53115 Bonn, Germany \\ ${ }^{\ddagger}$ Department of Mathematics and Natural Sciences, Gulf University for Science and Technology, Hawally 32093, Kuwait \\ ${ }^{\S}$ Chemistry Department, University of Fribourg, chemin du Musée 9, CH-1700 Fribourg, Switzerland
}

\begin{abstract}
Stacked dimers of four polycondensed aromatic hydrocarbons, with structures varying from high to reduced symmetries, have been calculated with dispersion-corrected density functional theory. The configurations of the stacked dimers are readily classified by two in-plane displacements and a relative rotation. The potential energy surface in these three coordinates was calculated with rigid monomers and appears to be slightly flat. Full geometry optimization was performed for selected

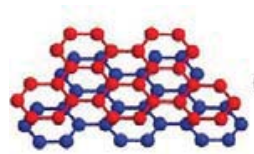

Syn

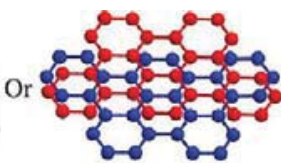

Anti low-energy structures, resulting in an energy ranking of a series of conformations whose geometries were characterized in considerable detail. The dissociation energy values reveal a clear preference for the symmetrical disk-shaped and triangular structures to dimerize into two in-plane-displaced arrangements, whereas the less symmetrical trapezoidal structures show a tendency to stack in displaced antiparallel over parallel arrangements. According to methodical checks, the key computational results, namely, the shape of the potential energy surface and the geometrical structures and energy ranking of dimer conformations, are essentially insensitive to computational assumptions such as the atomic orbital basis set and density functional chosen. This is shown in particular for the basis set superposition error, which, for the selected level of theory [B97-D3(BJ)/ $\operatorname{TZV}(\mathrm{d}, \mathrm{p})]$ was estimated by the counterpoise correction procedure to be in the narrow range between $7 \%$ and $8 \%$ of the uncorrected dissociation energies.
\end{abstract}

\section{INTRODUCTION}

The significant stability and unrivaled noncovalent $\pi-\pi$ stacking ${ }^{1}$ bonding that confer self-assembled polycondensed aromatic hydrocarbons (PAHs) with superior physicochemi$\mathrm{cal}^{2 \mathrm{a}-\mathrm{g}}$ and optoelectronic ${ }^{3 \mathrm{a}-\mathrm{k}}$ properties have drawn considerable attention in the past two decades. To simplify their synthesis, experimental efforts have focused on making highly symmetrical PAHs with structures ranging from linear to diskshaped. ${ }^{4 a-i}$ Nevertheless, the high symmetry of these structures complicates their uneven decoration with lateral groups (i.e., solubilizing aliphatic chains). A more convenient approach is to synthesize multisubstituted PAHs with analogous lateral groups, which hinders the stacking of the aromatic core by reducing the desired $\pi-\pi$ noncovalent bonding. ${ }^{5 a, b}$

We are interested in exploring the $\pi-\pi$ stacking of $\mathrm{PAH}$ structures whose reduced symmetry allows a disproportionate decoration with lateral groups. Among others, the half-lunar tribenzo[ $[f g, i j, r s t]$ pentaphene $(1, T B P$; Figure 1 with $\mathrm{R}=\mathrm{H})$ is believed to be a potential candidate. Derivatives of this compound substituted by a wide variety of pending groups have been explored as materials for optoelectronic devices. ${ }^{\text {a,b }}$ Furthermore, a TBP derivative substituted in all six positions by alkyl chains has also been reported but was not further investigated. ${ }^{7}$ To minimize steric hindrance that reduces $\pi-\pi$ stacking, we recently reported a versatile synthesis of TBP derivatives bearing pairs of alkyl side chains at the specific positions $\mathrm{R}_{1}, \mathrm{R}_{2}$, and $\mathrm{R}_{3}$ (Figure 1$) .^{8}$

As a result of its planar chirality, different stacking geometries are possible for $\mathbf{1}(\mathrm{TBP}, \mathrm{R}=\mathrm{H})$. Thus, we show in this

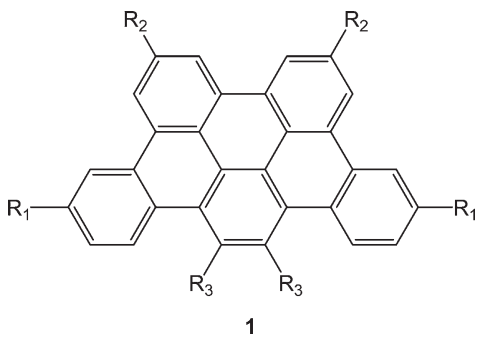

Figure 1. Structure of tribenzo[fg,ij,rst $]$ pentaphene (TBP, 1), indicating the three possible substitution sites.

computational study all of the possible $\pi-\pi$-stacked dimer conformations. To gain insight into the influence of structural symmetry on $\pi-\pi$ stacking, we also compare the most stable dimers of 1 with those of three other PAH structures (Figure 2): a stretched version of TBP, namely, dibenzo[ $f g, m n]$ phenanthro $\left[2,1,10,9,8,7-v w x y z a_{1} b_{1}\right]$ heptaphene $(\mathrm{DPH}, 2)$; the more symmetrical disk-shaped hexa-peri-hexabenzocoronene $(\mathrm{HBC}, 3)$, which also has the same number of $\mathrm{sp}^{2}$ carbon atoms as 2 ; and finally, a triangular structure, namely, benzo[o]bistriphenyleno $\left[2,1,12,11\right.$-efghi: $2^{\prime}, 1^{\prime}, 12^{\prime}, 11^{\prime}$-uvabc] ovalene $(\mathrm{BBO}, 4)$, which has twice the number of $\mathrm{sp}^{2}$ carbon atoms as compared to $\mathbf{1}$. It is noteworthy that little is known about the shape dependence of the potential energy surface (PES) for 


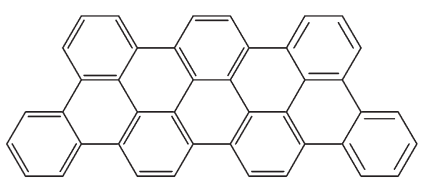

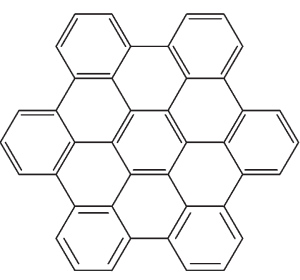

3

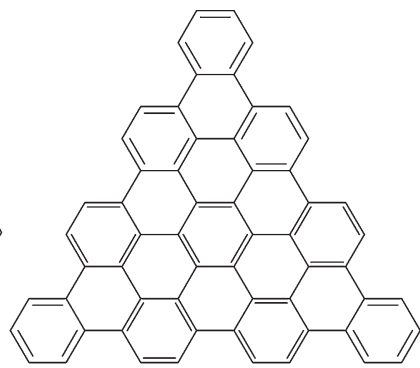

4

Figure 2. Structures of DPH (2), HBC (3), and BBO (4).

laterally displaced $\mathrm{PAH}$ dimers when their symmetry becomes reduced. In addition, it is not clear how different conceivable orientations of the PAHs in the dimer are arranged energetically. Therefore, a systematic computational study was conducted on the PESs and stationary points of all of the dimers of the listed compounds.

It is worthwhile to mention that only a few PAH dimers beyond the size of naphthalene $e^{9 a-c}$ have been treated at a comparable level of theory, ${ }^{10 a-d}$ where most of the theoretical investigations carried out to predict the structure/property relationships of various $\mathrm{PAH}$ structures have either studied their self-assembly in the bulk ${ }^{11}$ or focused on their single molecular structures, taking little or no notice of the way they interact molecularly. ${ }^{5 \mathrm{a}, 12}$

\section{COMPUTATIONAL METHODS}

Energies were calculated and geometries optimized with the dispersion-corrected density functional theory (DFT-D) developed by Grimme and co-workers ${ }^{13,14}$ using the B97-D generalized gradient approximation (GGA) functional ${ }^{13}$ and the new DFT-D version refined in terms of higher accuracy, broader range of applicability, and less empiricism. ${ }^{15 a, b}$ B97-D is a reparameterization of the $\mathrm{B} 97$ functional ${ }^{16}$ in the presence of the (so-called D2) dispersion correction. The zeroth-, first-, and second-order expansion coefficients of the power series in the remapped reduced gradient variable representing the gradient correction factors to the local energy densities of a uniform electron gas for the exchange and opposite- and same-spin contributions to the exchange-correlation functional (a total of nine parameters) were refitted as described in ref 13 . In the current work, the electronic part of B97-D was used in its original, unmodified form together with the more recent D3 version of ref $15 \mathrm{a}$ and a damping scheme according to Becke and Johnson $(\mathrm{BJ})^{15 \mathrm{~b}}$ to merge the description of the long-range correlation effects by the dispersion correction with the density functional's representation of short- and medium-range correlation effects. In addition to the scaling factor of the eighth-order dispersion contribution $\left(s_{8}\right)$, a scaling factor and shift of the atom-pair-specific cutoff radii were introduced to adjust the dispersion correction to the density functional. The three parameters in the $\mathrm{BJ}$ damping were determined by a leastsquares fit to a total of 130 reference energies in noncovalent interaction energy benchmark sets. ${ }^{15 \mathrm{~b}}$

For the S22 set of intermolecular interaction energies, ${ }^{17}$ B97$\mathrm{D} 3(\mathrm{BJ})$ has a mean absolute deviation (MAD) of $0.38 \mathrm{kcal}$ mol $^{-1}$ obtained with the def2-QZVP basis set. ${ }^{18}$ Because the S22 set is part of the fit set, the performance of B97-D for the S66 and S66 $\times 8$ sets $^{19}$ was tested, leading to MADs of 0.29 and $0.27 \mathrm{kcal} \mathrm{mol}^{-1}$ (def2-QZVP basis set), respectively. ${ }^{20}$ Note- worthy are the balanced descriptions of both equilibrium and nonequilibrium structures as represented by the S66 and S66 X 8 sets and between the different interaction types in the three subsets of S66 with B97-D reported in ref 20. In another benchmark on noncovalent interactions in smaller complexes, B97-D was the best-performing GGA density functional. ${ }^{21}$ Furthermore, B97-D was found to be the "best DFT" method in a recent benchmark on protein-ligand model complexes. ${ }^{22}$ This robustness of the B97-D functional has led to a series of successful practical applications. ${ }^{23}$ Therefore, we are convinced that B97-D is the right tool for our study.

Large Gaussian atomic-orbital ( $\mathrm{AO}$ ) basis sets of polarized triple- (TZVP) and quadruple- (QZVP) $\zeta$ quality $^{24}$ were employed. Density fitting techniques, also called the resolutionof-the-identity (RI) approximation, were used throughout to accelerate DFT-GGA computations ${ }^{25 a, b}$ roughly by a factor of $10-20$ at insignificant extra inaccuracy. All results were obtained with a slightly modified version of the Turbomole program package. ${ }^{26}$ The Gaussian AO basis sets were taken from the Turbomole library. ${ }^{27}$ The magnitude of the basis set superposition error (BSSE) was estimated with the counterpoise (CP) correction procedure. ${ }^{28}$ The self-consistent-field (SCF) convergence criterion for the increment of the total energy was $<10^{-7} E_{\mathrm{h}}$, and that for the increment of the oneelectron energy was $<10^{-4} E_{\mathrm{h}}$. The geometry convergence criterion for the total SCF energy was $10^{-7} E_{\mathrm{h}}$, and that for the maximum norm of the SCF energy gradient was $10^{-3} E_{h} / a_{0}$. For the quadrature of exchange correlation terms, the multiple grid $\mathrm{m} 4$ was specified. All other computational parameters were chosen as their default values.

\section{PROCEDURE}

The monomers of the investigated polycondensed aromatic hydrocarbon compounds TBP (1), DPH (2), HBC (3), and BBO (4) were optimized first. The resulting total energies were taken as reference for the dimer energies, and the potential energy surfaces of the dimers were explored with rigid monomers. For the fully stacked dimers, the interplane distance was varied from 3.23 to $3.97 \AA$ in steps of $0.053 \AA$. At the fixed separation of $3.35 \AA$ (the experimental interlayer spacing of graphene), the two monomers were displaced in-plane in two directions: from 0.0 to $2.38 \AA$ in steps of $0.265 \AA$ along the molecular axes starting from the fully stacked structure of the dimers of compounds $1-4$ and from 0.0 to $2.38 \AA$ along the long molecular axis and from -2.38 to $2.38 \AA$ along the short molecular axis in steps of $0.265 \AA$ in the $180^{\circ}$-rotated antiparallel structure of the dimers of compounds 1,2 , and 4 . The structures corresponding to the local minima of the potential energy surfaces were fully energy minimized. 
Table 1. B97-D3(BJ)/TZV(d,p) Energies ${ }^{a}\left(D_{e}, \mathrm{kcal} \mathrm{mol}^{-1}\right)$ of Dimers of 1-4 Polyaromatic Compounds

\begin{tabular}{|c|c|c|c|c|c|c|c|c|c|}
\hline parameter $^{b}$ & A & $\mathrm{B}$ & $\mathrm{C}$ & $\mathrm{D}$ & $\mathrm{E}$ & $\mathrm{F}$ & G & $\mathrm{H}$ & I \\
\hline & \multicolumn{9}{|c|}{ Tribenzo $[f g, i j, r s t]$ pentaphene $\left(1, \mathrm{C}_{30} \mathrm{H}_{16}\right) \Delta z=0.089 \AA$} \\
\hline$D_{\mathrm{e}}$ & 35.3 & 35.2 & 35.1 & 33.7 & 33.6 & 33.1 & 33.1 & $25.7^{d}$ & \\
\hline$D_{\mathrm{e}} / 30$ & 1.2 & 1.2 & 1.2 & 1.1 & 1.1 & 1.1 & 1.1 & $0.9^{d}$ & \\
\hline$D_{\mathrm{e}}-\mathrm{CP}$ & 32.6 & 32.6 & 32.6 & 31.0 & 31.1 & 30.7 & 30.6 & $23.8^{d}$ & \\
\hline$R_{\mathrm{e}}$ & 3.27 & 3.30 & 3.32 & $3.32 / 3.34$ & 3.35 & 3.41 & $3.35 / 3.35$ & $3.62^{d}$ & \\
\hline$\Delta z$ & 0.059 & 0.052 & 0.044 & $0.051 / 0.045$ & 0.073 & 0.118 & $0.046 / 0.021$ & $0.015^{d}$ & \\
\hline$R_{1}$ & 1.42 & 0.50 & 0 & $0.84 / 0.89$ & 1.60 & 1.01 & $0.01 / 0$ & 0 & \\
\hline$R_{2}$ & 0.73 & -0.80 & -0.78 & $1.40 / 1.36$ & 0.03 & 0.12 & $1.51 / 1.52$ & 0.01 & \\
\hline$\alpha$ & 180 & 180 & 180 & 2 & 1 & 18 & 0 & 0 & \\
\hline$D_{\mathrm{e}}(\mathrm{QZVP})^{e}$ & 34.5 & 34.5 & 34.5 & 33.0 & 33.0 & 32.4 & 32.6 & 25.4 & \\
\hline$D_{\mathrm{e}}-\mathrm{CP}^{e}$ & 33.9 & 34.0 & 33.9 & 32.4 & 32.4 & 31.9 & 32.0 & 24.9 & \\
\hline$D_{\mathrm{e}}(\mathrm{TPSS})^{f}$ & 30.0 & 30.0 & 29.7 & 28.6 & 28.6 & 27.6 & 27.9 & 21.6 & \\
\hline \multirow[t]{2}{*}{$D_{\mathrm{e}}-\mathrm{CP}^{f}$} & 29.1 & 29.1 & 28.8 & 27.7 & 27.7 & 26.8 & 27.0 & 20.8 & \\
\hline & \multicolumn{9}{|c|}{ Dibenzo $[f g, m n]$ phenanthro $\left[2,1,10,9,8,7-v w x y z a_{1} b_{1}\right]$ heptaphene $\left(2, \mathrm{C}_{42} \mathrm{H}_{20}\right) \Delta z=0.008 \AA$} \\
\hline$D_{\mathrm{e}}$ & 51.5 & 51.5 & 51.4 & 50.0 & 49.9 & 49.1 & 49.0 & 48.7 & $38.7^{d}$ \\
\hline$D_{\mathrm{e}} / 42$ & 1.2 & 1.2 & 1.2 & 1.2 & 1.2 & 1.2 & 1.2 & 1.2 & $0.9^{d}$ \\
\hline$D_{\mathrm{e}}-C P$ & 47.6 & 47.5 & 47.5 & 46.1 & 45.9 & 45.5 & 45.5 & 45.0 & $35.8^{d}$ \\
\hline$R_{\mathrm{e}}$ & 3.27 & 3.30 & 3.31 & $3.32 / 3.32$ & 3.35 & 3.39 & $3.34 / 3.34$ & 3.31 & $3.60^{d}$ \\
\hline$\Delta z$ & 0.052 & 0.050 & 0.047 & $0.050 / 0.030$ & 0.027 & 0.131 & $0.063 / 0.042$ & 0.045 & $0.018^{d}$ \\
\hline$R_{1}$ & 1.41 & 0.57 & 0.56 & $0.79 / 0.78$ & 1.57 & 1.16 & $0 / 0$ & 2.69 & 0 \\
\hline$R_{2}$ & 0.89 & -0.58 & 0.57 & $1.38 / 1.37$ & 0.02 & 0.06 & $1.48 / 1.49$ & 0 & 0.01 \\
\hline \multirow[t]{2}{*}{$\alpha$} & 180 & 180 & 180 & 0 & 1 & 10 & 0 & 0 & 0 \\
\hline & \multicolumn{9}{|c|}{ Hexa-peri-hexabenzocoronene $\left(3, \mathrm{C}_{42} \mathrm{H}_{18}\right) \Delta z=0.092 \AA$} \\
\hline$D_{\mathrm{e}}$ & 51.4 & 50.4 & 50.3 & $41.5^{g}$ & & & & & \\
\hline$D_{\mathrm{e}} / 42$ & 1.2 & 1.2 & 1.2 & $1.0^{g}$ & & & & & \\
\hline$D_{\mathrm{e}}-C P$ & 47.6 & 46.7 & 46.8 & $38.4^{g}$ & & & & & \\
\hline$R_{\mathrm{e}}$ & 3.34 & 3.39 & 3.35 & $3.58^{g}$ & & & & & \\
\hline$\Delta z$ & 0.072 & 0.069 & 0.009 & $0.154^{g}$ & & & & & \\
\hline$R_{1}{ }^{h}$ & 1.55 & 0.05 & 0 & 0.01 & & & & & \\
\hline$R_{2}^{I}$ & 0 & 0.03 & 1.43 & 0 & & & & & \\
\hline \multirow[t]{2}{*}{$\alpha$} & 0 & 21 & 0 & 0 & & & & & \\
\hline & \multicolumn{9}{|c|}{ Benzo[o] bistriphenyleno[2,1,12,11-efghi:2', $1^{\prime}, 12^{\prime}, 11^{\prime}$-uvabc] ovalene $\left(4, \mathrm{C}_{60} \mathrm{H}_{24}\right) \Delta z=0.007 \AA$} \\
\hline$D_{\mathrm{e}}$ & 76.3 & 74.9 & $74.9^{j}$ & 74.2 & 60.1 & & & & \\
\hline$D_{\mathrm{e}} / 60$ & 1.3 & 1.2 & $1.2^{j}$ & 1.2 & 1.0 & & & & \\
\hline$D_{\mathrm{e}}-C P$ & 70.4 & 69.8 & $69.5^{j}$ & 69.1 & 55.6 & & & & \\
\hline$R_{\mathrm{e}}$ & 3.32 & 3.31 & $3.34 / 3.35^{j}$ & 3.02 & 3.58 & & & & \\
\hline$\Delta z$ & 0.025 & 0.044 & $0.026 / 0.047^{j}$ & 0.217 & 0.026 & & & & \\
\hline$R_{1}{ }^{h}$ & 1.56 & 0.01 & $0 / 0$ & 0.08 & 0.01 & & & & \\
\hline$R_{2}^{I}$ & 0.01 & -0.01 & $1.44 / 1.42$ & 1.24 & 0 & & & & \\
\hline$\alpha$ & 0 & 20 & 0 & 180 & 0 & & & & \\
\hline
\end{tabular}

${ }^{a}$ Energy referred to relaxed monomers. ${ }^{b}$ Interplanar distance, $R_{\mathrm{e}}$; mean distance of carbon atoms from the rms plane, $\Delta z$; displacements along the long $\left(R_{1}\right)$ and short $\left(R_{2}\right)$ molecular axes $(\AA),{ }^{c}$ and angle between monomers, $\alpha$ (degrees). ${ }^{c}$ Two values given for nonequivalent monomers. ${ }^{d}$ Fully stacked (sandwich) structure obtained by imposing $\mathrm{C}_{2 \mathrm{v}}$ symmetry (optimization with $C_{1}$ symmetry leads to structure $\left.\mathbf{1} / \mathbf{2}-\mathrm{F}\right)$. ${ }^{e} \mathrm{~B} 97-\mathrm{D} 3$ (BJ)/ QZV(3d2f1g,3p2d1f) single-point energy. ${ }^{f}$ TPSS-D3(BJ)/QZV(3d2f1g,3p2d1f) single-point energy. ${ }^{g}$ Fully stacked (sandwich) structure obtained by imposing $D_{3 d}$ symmetry (optimization with $C_{1}$ symmetry leads to structure $3-B$ ). ${ }^{h}$ Displacement along a C-C bond. ${ }^{I}$ Displacement perpendicular to a $\mathrm{C}-\mathrm{C}$ bond. ${ }^{j}$ Parallel-displaced structure obtained by imposing $\mathrm{C}_{s}$ symmetry (optimization with $\mathrm{C}_{1}$ symmetry leads to structure 4 - $\mathrm{A}$ ).

\section{RESULTS AND DISCUSSION}

Tribenzopentaphene (TBP, 1) and Dibenzophenanthroheptaphene (DPH, 2). Whereas 1 is slightly distorted, 2 is practically planar, and the mean distance of the carbon atoms from the root-mean-square (rms) plane amounts to 0.089 and $0.008 \AA$ for B97-D3(BJ)/TZVP-optimized monomers of TBP and $\mathrm{DPH}$, respectively (see Table 1 ). The fully stacked dimers have a potential energy minimum at an interplane distance of $3.6 \AA$, with interaction energies of -25.4 and $-38.1 \mathrm{kcal} \mathrm{mol}^{-1}$ for rigid $\mathrm{TBP}$ and $\mathrm{DPH}$, respectively.

The potential energy surfaces for the stacked dimer of rigid $\mathbf{1}$ starting from the fully stacked and $180^{\circ}$-rotated structures are shown in Figure 3. The intermolecular interaction energy varies from -33.2 to $-20.4 \mathrm{kcal} \mathrm{mol}^{-1}$ for the parallel dimers and from -34.3 to $-22.4 \mathrm{kcal} \mathrm{mol}^{-1}$ for the antiparallel dimers. For the parallel-displaced structure (Figure 3, left), the potential energy minimum corresponds to a displacement of about $1.5 \AA$ irrespective of the direction, that is, along a molecular axis or between them. For smaller displacements, the energy increases steeply, with the energy maximum at the fully stacked structure about $13 \mathrm{kcal} \mathrm{mol}^{-1}$ above the minimum. For larger in-plane displacements, the energy increases more smoothly to local maximum values about $5 \mathrm{kcal} \mathrm{mol}^{-1}$ above the minimum and to saddle-point values about $2 \mathrm{kcal} \mathrm{mol}^{-1}$ above the minimum between the local maxima.

The potential energy minimum for the antiparallel-displaced structure (Figure 3, right) corresponds to smaller displacements 

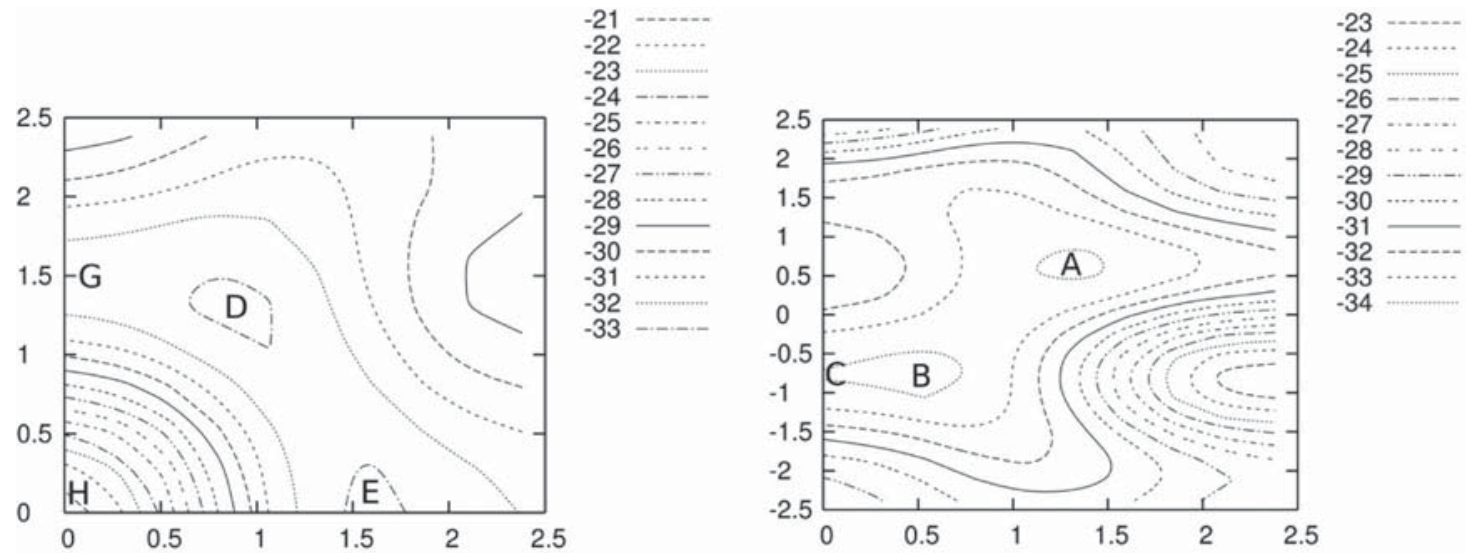

Figure 3. B97-D3(BJ)/TZV $(\mathrm{d}, \mathrm{p})$ interaction energy surface of the displaced parallel and antiparallel stacked dimers. The origin on the left corresponds to the fully stacked structure; the origin on the right corresponds to the $180^{\circ}$-rotated structure. Displacement along the long molecular axis refers to the abscissa $\left(R_{1}\right)$, and that along the short molecular axis refers to the ordinate $\left(R_{2}\right)$. Contours in $\mathrm{kcal} \mathrm{mol}^{-1}$; axes in $\AA$. The interplane spacing $\left(R_{\mathrm{e}}\right)$ is $3.35 \AA$.

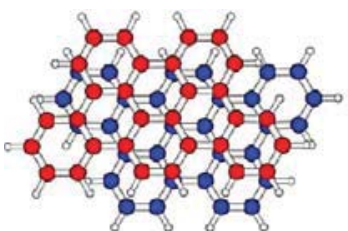

1-A
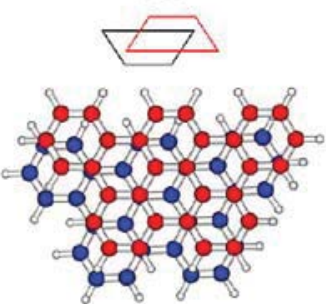

1-D
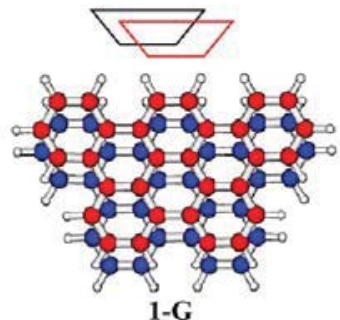

1-G

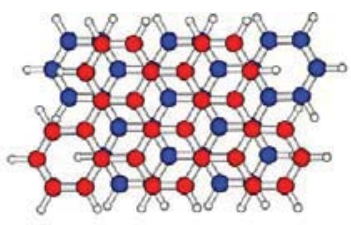

1-B

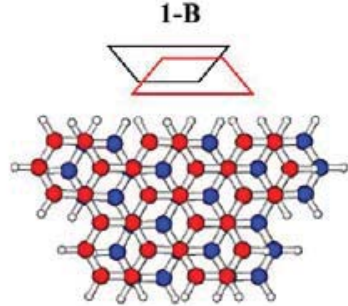

1-E

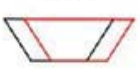

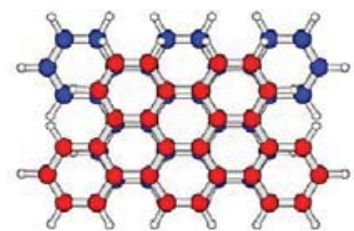

1-C

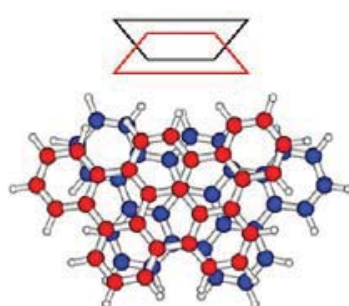

1-F
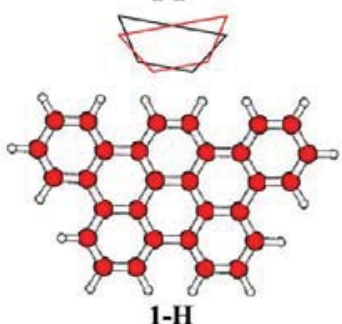

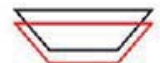

Figure 4. B97-D3(BJ)/TZV(d,p)-optimized structures of tribenzo[fg,ij,rst $]$ pentaphene dimers.

of about $1 \AA$ from the maximally overlapping structure. Displacements are not equivalent for all opposite directions; rather, those along the short molecular axis with larger overlap of the monomers (positive $R_{2}$ direction) are energetically different from equally large displacements with smaller overlap of the monomers (negative $R_{2}$ direction). The structure with maximum overlap of the monomers is not an energy maximum in this case and is only $2 \mathrm{kcal} \mathrm{mol}^{-1}$ above the potential energy minimum at $R_{1}=0.5 \AA$ and $R_{2}=0.8 \AA$. The potential energy maximum corresponds to displacements of about 2.4 and $0.8 \AA$ along the long and short molecular axes (in the $R_{1}$ and $R_{2}$ directions), respectively, with $12 \mathrm{kcal} \mathrm{mol}^{-1}$ higher energy than the potential energy minimum. Altogether, large in-plane displacements correspond to small energy variations on the order of thermal energies, that is, the molecules are laterally almost freely mobile in the dimer.

Figure 4 shows the structures of stationary points for dimers of 1 (see Table 1 for dissociation energies and geometrical data). The fully stacked structure (1-H), which has a dissociation energy of $25.7 \mathrm{kcal} \mathrm{mol}^{-1}$, is obtained by imposing $C_{2 v}$ symmetry. Optimization without symmetry constraints leads to structure $1-\mathrm{F}$ with the monomers rotated by $18^{\circ}$; thus, structure $\mathbf{1 - H}$ is not a local minimum. All freely (i.e., without symmetry constraints) optimized structures have dissociation energies in the range from 33.1 to $35.3 \mathrm{kcal} \mathrm{mol}^{-1}$. The three structures with the lowest energies, 1-A, 1-B, and 1-C, are antiparallel-displaced dimers (in structure $\mathbf{1 - A}$, the displacement along the short molecular axis of structure 1-B is 

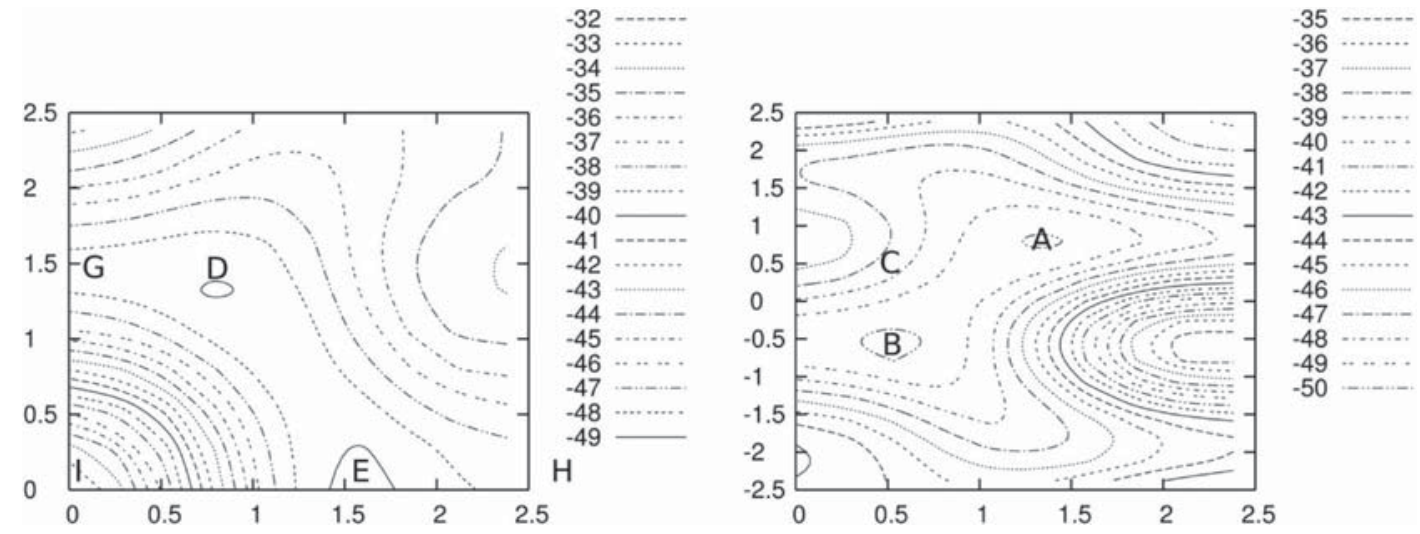

Figure 5. B97-D3(BJ)/TZV(d,p) interaction energy surface of the stacked DPH dimers displaced parallel (left) and antiparallel (right). The origin on the left corresponds to the fully stacked structure; the origin on the right corresponds to the $180^{\circ}$-rotated structure. Displacement along the long molecular axis refers to the abscissa $\left(R_{1}\right)$, and that along the short molecular axis refers to the ordinate $\left(R_{2}\right)$. Contours in kcal mol ${ }^{-1}$; axes in $\AA$. The interplane spacing $\left(R_{\mathrm{e}}\right)$ is $3.35 \AA$.
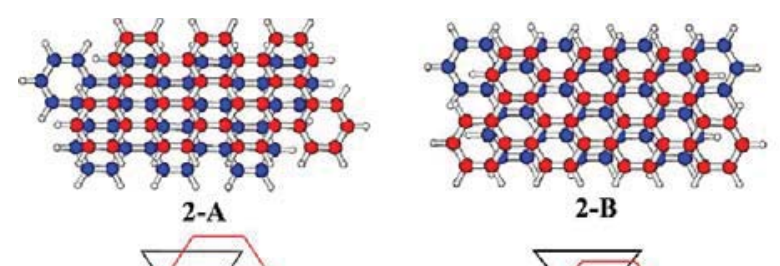

2-B
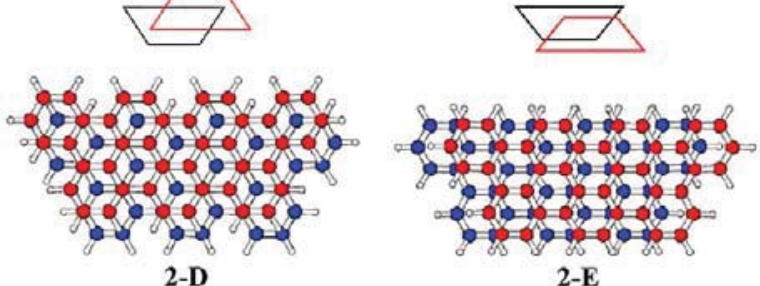

2-E
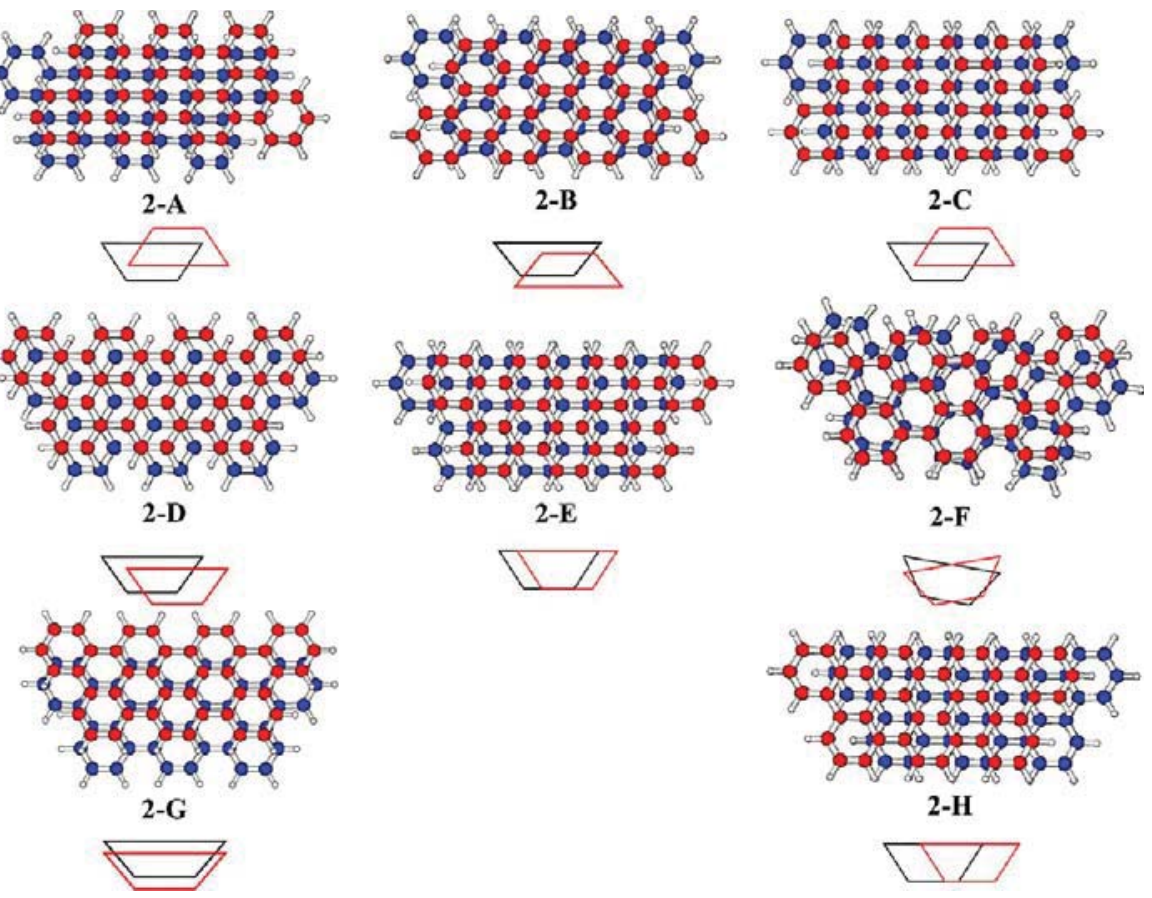

Figure 6. B97-D3(BJ)/TZV(d,p)-optimized structures of DPH dimers.

reversed). The parallel-displaced structure with the lowest energy (1-D) is $1.6 \mathrm{kcal} \mathrm{mol}^{-1}$ higher in energy than the lowestenergy structure. Parallel-displaced structures with a displacement only along the long (1-E) or short (1-G) molecular axis are 0.1 or $0.6 \mathrm{kcal} \mathrm{mol}^{-1}$ higher in energy, respectively.

An antiparallel-displaced structure with a displacement only along the long molecular axis could not be identified as a minimum of the potential energy. Optimization starting from an antiparallel dimer displaced along the long molecular axis resulted in structure 1-B. Starting from an antiparallel dimer displaced along the short molecular axis in the positive direction gave structure 1-A. The dissociation energies per carbon atom are $1.2 \mathrm{kcal} \mathrm{mol}^{-1}$ for the antiparallel-displaced dimers, $1.1 \mathrm{kcal} \mathrm{mol}^{-1}$ for the parallel-displaced dimers, and 0.9 $\mathrm{kcal} \mathrm{mol}^{-1}$ for the fully stacked dimer.

The interplanar distance $\left(R_{\mathrm{e}}\right)$ of the fully optimized dimers (Table 1) varies from 3.27 to $3.41 \AA$. A rough correlation between $R_{\mathrm{e}}$ and the dissociation energy $\left(D_{\mathrm{e}}\right)$ is observed. In particular, the most strongly bound dimer 1-A also has the shortest interplanar distance. The mean distance of the carbon atoms in one monomer from the rms plane of the same monomer $(\Delta z)$ is a measure for the deformation the monomers experience upon formation of the dimer. It varies from 0.021 to $0.073 \AA$ for parallel-displaced dimers of 1 and from 0.044 to $0.059 \AA$ for antiparallel-displaced dimers of $\mathbf{1}$, in comparison to the $\Delta z$ value of $0.089 \AA$ for isolated tribenzo $[f g, i j, r s t]$ pentaphene $\mathbf{1}$. The largest deformation occurs for the rotated dimer $1-F$, with $\Delta z=0.118 \AA$. To determine the displacements along the molecular axes $R_{1}$ and $R_{2}$, the difference vector between the centers of the carbon atoms in the two monomers is projected into the rms plane of one of the monomers (the length of the projection of the same difference vector onto the normal of the rms plane is $R_{\mathrm{e}}$ ). For the long molecular axis, the projection of the direction along a $\mathrm{C}-\mathrm{C}$ bond vector into the same rms plane is taken. Since all the geometrical data depend on which of the monomers is chosen 


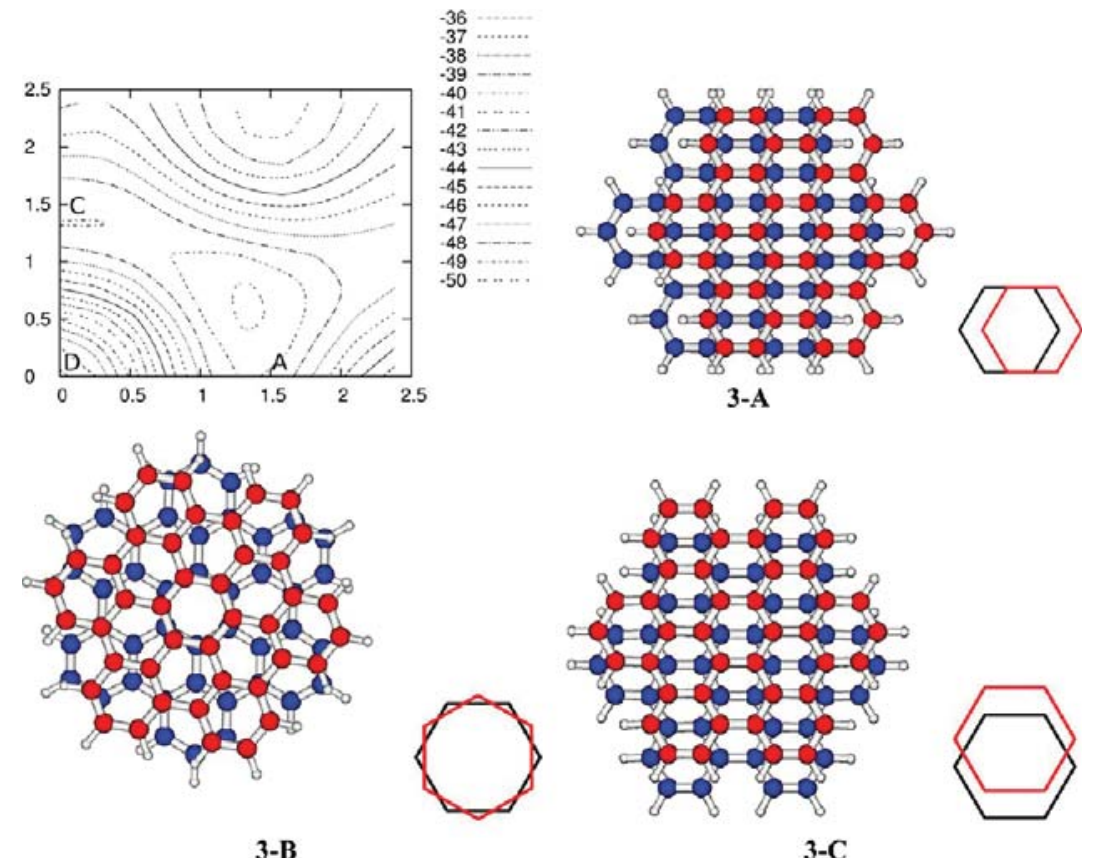

Figure 7. B97-D3(BJ)/TZV (d,p) interaction energy surface of HBC stacked dimers displaced parallel (top left). The origin corresponds to the fully stacked structure. Displacements along a $\mathrm{C}-\mathrm{C}$ bond refer to the abcissa $\left(R_{1}\right)$; displacements perpendicular to a C $-\mathrm{C}$ bond refer to the ordinate $\left(R_{2}\right)$. Contours in $\mathrm{kcal} \mathrm{mol}^{-1}$; axes in $\AA$. The interplane spacing $\left(R_{\mathrm{e}}\right)$ is $3.35 \AA$. B97-D3(BJ)/TZV $(\mathrm{d}, \mathrm{p})$-optimized structures of HBC dimers.

to base the calculation upon, two values are given for the structures that have nonequivalent monomers (1-D and 1-G). The minimum-energy structure of the antiparallel dimer 1-A is displaced along the long molecular axis by about $1.42 \AA$ and along the short molecular axis by about $0.73 \AA$, whereas the isoenergetic structure 1-B (only $0.1 \mathrm{kcal} \mathrm{mol}^{-1}$ higher in energy) has $R_{1}$ and $R_{2}$ values of 0.50 and $-0.80 \AA$, respectively. The minimum-energy structure of the parallel dimer 1-D is displaced along $R_{1}$ by $0.84 / 0.89 \AA$ and along $R_{2}$ by $1.40 / 1.36 \AA$. Parallel dimers with a displacement only along the long (1-E) or short (1-G) molecular axis are displaced by 1.60 and 1.51 / $1.52 \AA$, respectively.

The counterpoise (CP) correction for the fully optimized structures varies from 2.4 to $2.7 \mathrm{kcal} \mathrm{mol}^{-1}$; the $\mathrm{CP}$ correction of the fully stacked structure $\mathbf{1 - H}$ is $1.9 \mathrm{kcal} \mathrm{mol}^{-1}$. These values are $7.1-7.8 \%$ of the uncorrected dissociation energies $\left(D_{\mathrm{e}}\right)$. Therefore, the sequence is unaffected by CP correction (Table 1). As a methodical check, we also applied the large QZVP basis for single-point energy calculations (see Table 1). The dissociation energy is reduced by less than $1 \mathrm{kcal} \mathrm{mol}^{-1}(0.3-$ $\left.0.8 \mathrm{kcal} \mathrm{mol}^{-1}\right)$. The overall energy ordering among antiparallel-displaced, parallel-displaced, and fully stacked structures is not affected; only the sequence between the closely lying conformers $\mathbf{F}$ and $\mathbf{G}$ is reversed. The CP correction varies between 0.5 and $0.6 \mathrm{kcal} \mathrm{mol}^{-1}$ or between $1.5 \%$ and $1.9 \%$ of $D_{\mathrm{e}}$. The same holds when applying the metaGGA TPSS $^{29}$ in place of B97-D, but in this case, the dissociation energies are reduced by about 4-5 $\mathrm{kcal} \mathrm{mol}^{-1}$ compared to the B97-D estimate $\left(3.8-4.8 \mathrm{kcal} \mathrm{mol}^{-1}\right)$, and the $\mathrm{CP}$ correction is larger $\left(0.8-0.9 \mathrm{kcal} \mathrm{mol}^{-1}\right.$, or $\left.2.9-3.6 \%\right)$.

The shape of the potential energy surface for the stacked dimer of $\mathbf{2}$ (Figure 5) closely resembles that of dimer $\mathbf{1}$ but shows, as expected, higher interaction energies that vary between -49.4 and $-32.0 \mathrm{kcal} \mathrm{mol}^{-1}$ for parallel dimers and between -50.2 and $-34.1 \mathrm{kcal} \mathrm{mol}^{-1}$ for antiparallel dimers. For the parallel-displaced structure, the fully stacked dimer again corresponds to an energy maximum $17 \mathrm{kcal} \mathrm{mol}^{-1}$ above the minimum located at a relative displacement of $1.6 \AA$. The local energy maxima at larger in-plane displacements are about $6 \mathrm{kcal} \mathrm{mol}^{-1}$ above the minimum, and the height of the saddle points between the local maxima is $4 \mathrm{kcal} \mathrm{mol}^{-1}$. For the antiparallel-displaced structure, two almost isoenergetic local minima occur at displacements from the maximally overlapping structure of $0.6 \AA$ along $R_{1}$ and $-0.6 \AA$ along $R_{2}$, as well as $1.4 \AA$ along $R_{1}$ and $0.9 \AA$ along $R_{2}$ (opposite direction from the other minimum). The global maximum of the potential energy surface corresponds to displacements of $2.1 \AA$ along $R_{1}$ and $-0.5 \AA$ along $R_{2}$ and is $\sim 16 \mathrm{kcal} \mathrm{mol}^{-1}$ higher in energy. The maximally overlapping structure is $2 \mathrm{kcal} \mathrm{mol}^{-1}$ above the minimum-energy structure.

The dissociation energies of the DPH (2) dimers are increased by a factor of 1.5 with respect to their "shorter" analogous TBP (1) dimers. Accordingly, the energy orderings of the dimeric structures of $\mathbf{1}$ and $\mathbf{2}$ are almost alike, with the antiparallel-displaced structures 2-A, 2-B, and 2-C having the lowest energies of $\sim 51.5 \mathrm{kcal} \mathrm{mol}^{-1}$ (see Figure 6). In addition, structure 2-D shows the lowest energy $\left(50.0 \mathrm{kcal} \mathrm{mol}^{-1}\right)$ for the parallel-displaced structures, which is $1.5 \mathrm{kcal} \mathrm{mol}^{-1}$ higher than the lowest-energy antiparallel structures. Parallel-displaced structures with displacements only along the long (2-E/-H) or short (2-G) molecular axis are $0.1 / 1.3$ and $1.0 \mathrm{kcal} \mathrm{mol}^{-1}$ higher in energy, respectively, than the lowest-energy paralleldisplaced structure 2-D. Again, the fully stacked structure 2-I could be obtained only by imposing $C_{2 v}$ symmetry, whereas unrestrained optimization starting from a fully stacked dimer resulted in structure 2-F with the monomers rotated by $10^{\circ}$. The dissociation energies per carbon atom are $1.2 \mathrm{kcal} \mathrm{mol}^{-1}$ in all cases, except for the fully stacked dimer, for which it amounts to $0.9 \mathrm{kcal} \mathrm{mol}^{-1}$. Likewise, size and variation of the $\mathrm{CP}$ correction for the stationary structures of DPH are larger than for TBP $\left(3.5-4.0 \mathrm{kcal} \mathrm{mol}^{-1}\right)$, and its application leaves the sequence unchanged. The smallest value $\left(2.8 \mathrm{kcal} \mathrm{mol}^{-1}\right)$ 

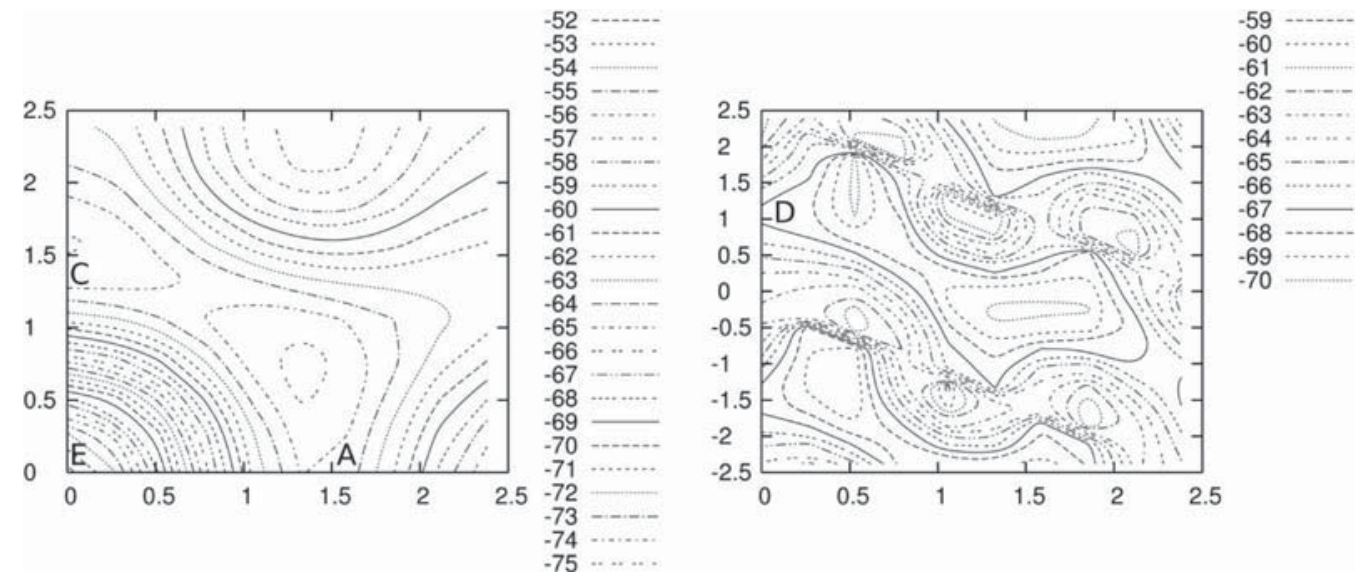

Figure 8. B97-D3(BJ)/TZV $(\mathrm{d}, \mathrm{p})$ interaction energy surface of the stacked BBO dimers displaced parallel (left) and antiparallel (right). The origin at the left corresponds to the fully stacked structure, and the origin at the right corresponds to the $180^{\circ}$-rotated structure. Displacements along a $\mathrm{C}-\mathrm{C}$ bond refer to the abcissa $\left(R_{1}\right)$; displacements perpendicular to a C-C bond refer to the ordinate $\left(R_{2}\right)$. Contours in kcal mol ${ }^{-1}$; axes in $\AA$. The interplane spacing $\left(R_{\mathrm{e}}\right)$ is $3.35 \AA$.

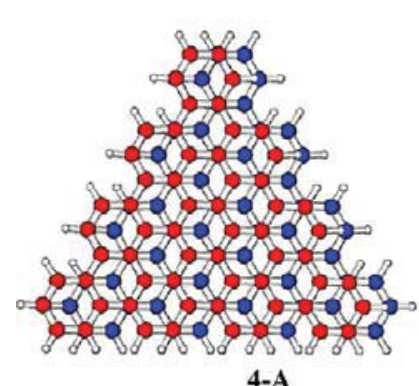

4-A

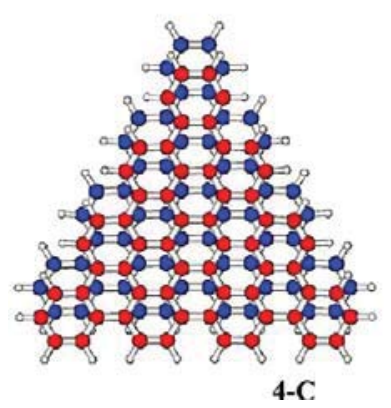

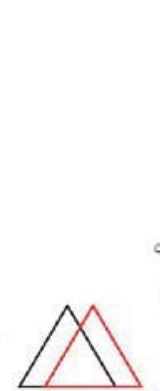

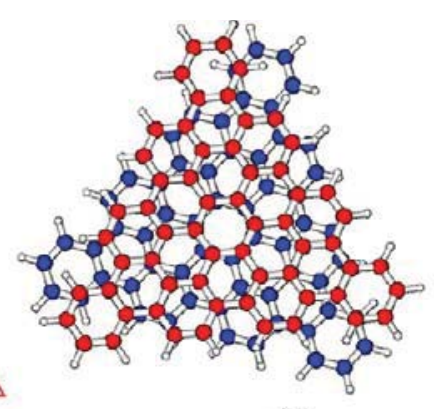

4-B

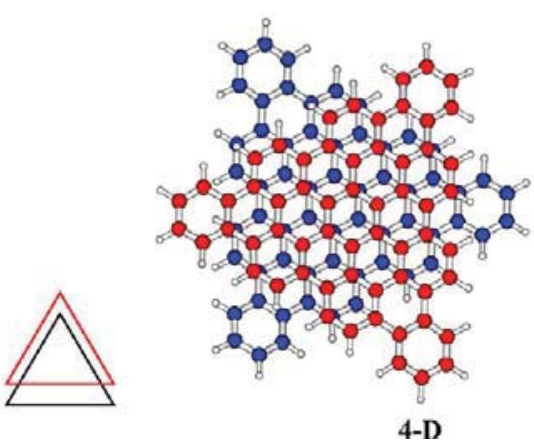

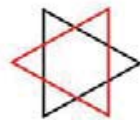

Figure 9. B97-D3(BJ)/TZV(d,p)-optimized structures of BBO dimers.

again occurs for the fully stacked structure 2 -I as a consequence of the larger intermolecular distance. The percentage of $D_{\mathrm{e}}$ varies from $7.2 \%$ to $8.0 \%$ as for TBP.

The interplane spacings of the DPH dimers are up to $0.02 \AA$ smaller than those of their corresponding dimers 1 . The mean distances of the carbon atoms from the rms plane increased to the ranges of $0.027-0.063 \AA$ for parallel-displaced dimers of 2 and $0.047-0.057 \AA$ for antiparallel-displaced dimers of 2, when compared to the $0.008 \AA$ value for the isolated structure 2 . The largest deformation of the monomers, $0.131 \AA$, occurs for the rotated dimer 2-F. Despite the difference in their absolute values, the $R_{1} / R_{2}$ displacements of the parallel dimers 2-D, 2$\mathbf{E} /-\mathbf{H}$, and 2-G and the antiparallel dimers $\mathbf{2}-\mathbf{A}$ and $\mathbf{2}-\mathbf{B}$ resemble those of their counterpart dimers 1 . This difference is most pronounced for the dimer structures $\mathbf{1 - C}$ and $\mathbf{2 - C}$ because of the flatness of the potential energy surfaces in terms of inplane displacements and rotation.
HBC (3) and BBO (4). The mean distance of the carbon atoms from the rms plane for the distorted molecule 3 and the planar molecule 4 is 0.092 and $0.007 \AA$, respectively. The reason for the larger distortion in 3 is the phenanthrene-like interaction that occurs between the adjacent peripheral benzene rings. The potential energy minima of the fully stacked dimers 3 and 4 occur at $3.6 \AA$, that is, at about the same interplane distance as for the $\mathbf{1}$ and $\mathbf{2}$ dimers, with respective interaction energies of -41.1 and $-59.2 \mathrm{kcal} \mathrm{mol}^{-1}$.

Figure 7 shows the potential energy surface of stacked dimers of 3 , at an interplane spacing of $3.35 \AA$, and three of its stationary dimers. The interaction energy varies from -35.7 to $-50.3 \mathrm{kcal} \mathrm{mol}^{-1}$. The global minimum occurs for displacements of $1.32 \AA$ along $\left(R_{1}\right)$ and $0.53 \AA$ perpendicular to $\left(R_{2}\right)$ the $\mathrm{C}-\mathrm{C}$ bonds. Another local minimum occurs for an $R_{1}$ value of $0.26 \AA$ and an $R_{2}$ value of $1.32 \AA$. The global maximum occurs for the fully stacked structure with an energy of $14.6 \mathrm{kcal}$ 
$\mathrm{mol}^{-1}$ over the minimum-energy structure. The parallel-shifted dimer 3-A has the lowest energy with a displacement along two opposite edges. On the other hand, parallel-shifted dimer 3-C with a displacement perpendicular to two opposite edges of the hexagon, has a $1.1 \mathrm{kcal} \mathrm{mol}^{-1}$ lower dissociation energy. Optimization of the fully stacked dimer without symmetry restriction leads to $3-\mathrm{B}$, with $21^{\circ}$-rotated monomers, which has almost the same energy as dimer 3-C. The fully stacked structure 3-D could be obtained only by imposing $D_{3 d}$ symmetry and has a $9.9 \mathrm{kcal} \mathrm{mol}^{-1}$ higher energy than the minimum-energy structure. Except for the fully stacked dimer $\left(1.0 \mathrm{kcal} \mathrm{mol}^{-1}\right)$, the dissociation energies per carbon atom amount to $1.2 \mathrm{kcal} \mathrm{mol}^{-1}$. The CP correction is $3.8 \mathrm{kcal} \mathrm{mol}^{-1}$ for structure 3-A, $3.6 \mathrm{kcal} \mathrm{mol}^{-1}$ for 3-B, $3.5 \mathrm{kcal} \mathrm{mol}^{-1}$ for 3-C, and $3.2 \mathrm{kcal} \mathrm{mol}^{-1}$ for $3-\mathrm{D}$, corresponding to $7.4 \%, 7.2 \%, 7.0 \%$, and $7.6 \%$ of $D_{\mathrm{e}}$, respectively.

The two parallel dimers 3-A and 3-C have the smallest interplane distances of 3.34 and $3.35 \AA$, respectively, whereas dimers 3-B and 3-D show separations of 3.39 and $3.58 \AA$, respectively. Dimer 3-D has a larger distortion of the monomers than the isolated structure 3, whereas for 3-A, 3$\mathbf{B}$, and $3-\mathbf{C}$, the mean distance of the carbon atoms from the rms plane is reduced. In dimers $\mathbf{3}-\mathbf{A}$ and $\mathbf{3}-\mathrm{C}$, the monomers are displaced by $1.55 \AA$ along a $\mathrm{C}-\mathrm{C}$ bond and by $1.43 \AA$ perpendicular to a $\mathrm{C}-\mathrm{C}$ bond, respectively.

The potential energy surface of the parallel-displaced stacked dimer 4-A ranges from -51.7 to $-75.5 \mathrm{kcal} \mathrm{mol}^{-1}$ (Figure 8, left). The minimum-energy structure is observed for a displacement of $1.32 \AA$ parallel $\left(R_{1}\right)$ and $0.79 \AA$ perpendicular $\left(R_{2}\right)$ to a $\mathrm{C}-\mathrm{C}$ bond. A second local minimum is obtained for a displacement of $1.59 \AA$ along only $R_{2}$. The fully stacked dimer shows the global maximum of the potential energy, with a 23.8 $\mathrm{kcal} \mathrm{mol}^{-1}$ less negative interaction energy. Other local maxima at symmetrically equivalent points on the $R_{1}-R_{2}$ plane are smaller because of the effect of the finite size of the BBO monomers. The potential energy surface of the antiparalleldisplaced stacked dimers 4-D (Figure 8, right) is highly irregular because of the predominance of the interaction effect between the edges of the monomers.

The structures obtained for the BBO (4) dimers are shown in Figure 9. The $180^{\circ}$-rotated structure 4-D is $2.1 \mathrm{kcal} \mathrm{mol}^{-1}$ higher in energy than the parallel-shifted 4-A. The other parallel-shifted dimer 4-C could only be optimized by imposing $C_{s}$ symmetry and is $1.4 \mathrm{kcal} \mathrm{mol}^{-1}$ higher in energy than structure 4-A. Finally, the fully stacked structure 4-E has a $D_{\mathrm{e}}$ of $60.1 \mathrm{kcal} \mathrm{mol}^{-1}$ and is thus $16.2 \mathrm{kcal} \mathrm{mol}^{-1}$ above the structure with the maximum dissociation energy, 4-A. The dissociation energy per carbon atom is equal to $1.3 \mathrm{kcal} \mathrm{mol}^{-1}$ for 4-A, 1.0 $\mathrm{kcal} \mathrm{mol}^{-1}$ for 4-E, and $1.2 \mathrm{kcal} \mathrm{mol}^{-1}$ for the remaining dimers (4-B, 4-C, and 4-D). The CP correction is between 4.5 and 5.9 $\mathrm{kcal} \mathrm{mol}{ }^{-1}$, or between $6.8 \%$ and $7.8 \%$ of $D_{\mathrm{e}}$, and leaves the sequence of structures unchanged.

The deformation of the monomers is larger than the value for isolated 4 for all dimers of 4: $0.025 \AA$ for the paralleldisplaced structure 4-A, 0.026/0.047 $\AA$ for the parallel-displaced structure 4-C, and $0.217 \AA$ for the $180^{\circ}$-rotated structure 4-D. The interplane spacing is $3.32 \AA$ for structure 4-A, $3.34 / 3.35 \AA$ for structure 4-C, and $3.02 \AA$ for structure 4-D, which, because of the strong deformation of the monomers, is smaller than the intermolecular distance. $R_{1}$ now stands for displacement along and $R_{2}$ for displacement perpendicular to a $\mathrm{C}-\mathrm{C}$ bond. In the parallel-displaced dimers $4-\mathbf{A}$ and $\mathbf{4}-\mathbf{C}$, the monomers are displaced by $1.56 \AA$ along and by $1.44 / 1.42 \AA$ perpendicular to a $\mathrm{C}-\mathrm{C}$ bond, respectively. On the other hand, the $180^{\circ}$-rotated structure $4-\mathrm{D}$ is shifted by $1.24 \AA$ perpendicular to a $\mathrm{C}-\mathrm{C}$ bond.

The energy diagram in Figure 10 summarizes the results for the stationary structures found by showing the B97-D3(BJ)/

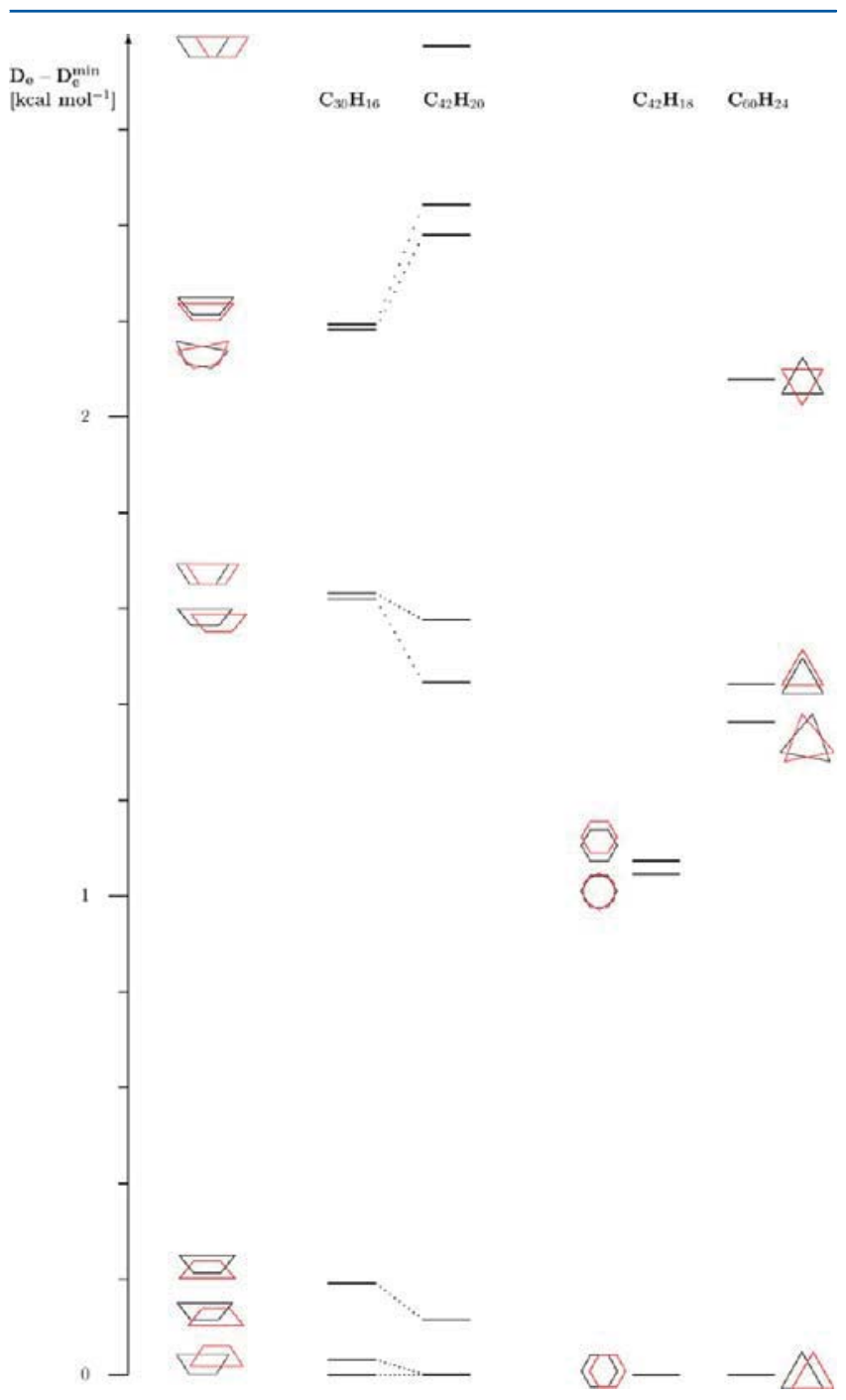

Figure 10. Relative B97-D3(BJ)/TZV (d,p) dissociation energies (kcal $\mathrm{mol}^{-1}$ ) for B97-D3(BJ)/TZV (d,p)-energy-minimized dimers of tribenzopentaphene $\left(\mathrm{C}_{30} \mathrm{H}_{16}\right)$, dibenzophenanthroheptaphene $\left(\mathrm{C}_{42} \mathrm{H}_{20}\right)$, hexabenzocoronene $\left(\mathrm{C}_{42} \mathrm{H}_{18}\right)$, and benzobistriphenylenoovalene $\left(\mathrm{C}_{60} \mathrm{H}_{24}\right)$.

$\operatorname{TZV}(\mathrm{d}, \mathrm{p})$ dissociation energies relative to that of the most stable structure. Although the individual dissociation energies for the dimers of $\mathbf{2}$ are 1.5 times as large as those of $\mathbf{1}$, the energy separation from the antiparallel- to the parallel-displaced dimers is slightly reduced as edge effects become less important compared to the underlying 6-fold symmetry of the potential for larger monomers. All in all, several stationary structures are accessible within a few kilocalories per mole from the most stable structure found, being separated by flat barriers.

\section{CONCLUSIONS}

By applying state-of-the-art quantum chemical methods, we characterized the potential energy surfaces and minimumenergy structures for the dimers of four polyaromatic 
hydrocarbons: tribenzopentaphene $\left(\mathrm{C}_{30} \mathrm{H}_{16}\right)$, dibenzophenanthroheptaphene $\left(\mathrm{C}_{42} \mathrm{H}_{20}\right)$, hexabenzocoronene $\left(\mathrm{C}_{42} \mathrm{H}_{18}\right)$, and benzobistriphenylenoovalene $\left(\mathrm{C}_{60} \mathrm{H}_{24}\right)$. The results of our dispersion-corrected density functional theory calculations clearly show a proportional relationship between the number of $\mathrm{sp}^{2}$ carbon atoms of the polycondensed aromatic hydrocarbons and the dissociation energy values of their respective stacked dimers. The latter also show a preference toward a displaced configuration over a fully stacked one, which can be explained by the repulsive nature that arises from the closedshell electron configurations of carbons. Thus, the potential energy surfaces of the dimers with a higher symmetry, that is, the hexagonal (3) and the triangular (4) structures, reveal a preferred displacement along the parallel $\mathrm{C}-\mathrm{C}$ bond with a restricted rotation. However, the dimers of the half-lunar structure 1 and its stretched homologue 2 have relatively flat potential energy surfaces but with an obvious tendency toward the antiparallel- over parallel-displaced $\pi-\pi$ stacking. Despite their tapered trapezoidal structures, the dimers of compounds 1 and 2 show good interaction energies and still account for a typical interplanar distance homologous to that of graphene.

\section{AUTHOR INFORMATION}

\section{Corresponding Author}

*E-mail: grimme@thch.uni-bonn.de.

\section{Author Contributions}

The manuscript was written through the contributions of all authors. All authors have given approval to the final version of the manuscript.

\section{Notes}

The authors declare no competing financial interest.

\section{REFERENCES}

(1) Grimme, S. Angew. Chem., Int. Ed. 2008, 47, 3430-3434 and references therein.

(2) (a) Aebischer, O. F.; Aebischer, A.; Donnio, B.; Alameddine, B.; Dadras, M.; Güdel, H.-U.; Guillon, D.; Jenny, T. A. J. Mater. Chem. 2007, 17, 1262-1267. (b) Wu, J.; Li, J.; Kolbb, U.; Müllen, K. Chem. Commun. 2006, 48-50. (c) Miao, Q.; Chi, X.; Xiao, S.; Zeis, R.; Lefenfeld, M.; Siegrist, T.; Steigerwald, M. L.; Nuckolls, C. J. Am. Chem. Soc. 2006, 128, 1340-1345. (d) Alameddine, B.; Aebischer, O. F.; Amrein, W.; Donnio, B.; Deschenaux, R.; Guillon, D.; Savary, C.; Scanu, D.; Scheidegger, O.; Jenny, T. A. Chem. Mater. 2005, 17, 47984807. (e) Bushby, R. J.; Lozman, O. R. Curr. Opin. Colloid Interface Sci. 2002, 7, 343-354. (f) O’Neill, M.; Kelly, S. M. Adv. Mater. 2003, 15, 1135-1146. (g) Van de Craats, A. M.; Stutzman, N.; Bunk, O.; Nielsen, M. M.; Watson, M.; Müllen, K.; Chanzy, H. D.; Sirringhaus, H.; Friend, R. H. Adv. Mater. 2003, 15, 495-499.

(3) (a) Mori, T.; Kikuzawa, Y.; Takeuchi, H. Org. Electron. 2008, 9, 328-332. (b) Hara, T.; Furukawa, K.; Nakamura, T.; Yamamoto, Y.; Kosaka, A.; Jin, W.; Fukushima, T.; Aida, T. J. Phys. Soc. Jpn. 2008, 77, 034710. (c) Sergeyev, S.; Pisula, W.; Geerts, Y. H. Chem. Soc. Rev. 2007, 36, 1902-1929. (d) Lloyd, M. T.; Mayer, A. C.; Tayi, A. S.; Bowen, A. M.; Kasen, T. G.; Herman, D. J.; Mourey, D. A.; Anthony, J. E.; Malliaras, G. G. Org. Electron. 2006, 7, 243-248. (e) Katz, H. E. Chem. Mater. 2004, 16, 4748-4756. (f) Moon, H.; Zeis, R; Borkent, E.-J.; Besnard, C.; Lovinger, A. J.; Siegrist, T.; Kloc, C.; Bao, Z. J. Am. Chem. Soc. 2004, 126, 15322-15323. (g) Xiao, S.; Tang, J.; Beetz, T.; Guo, X.; Tremblay, N.; Siegrist, T.; Zhu, Y.; Steigerwald, M.; Nuckolls, C. J. Am. Chem. Soc. 2006, 128, 10700-10701. (h) Pisula, W.; Menon, A.; Stepputat, M.; Lieberwirth, I.; Kolb, U.; Tracz, A.; Sirringhaus, H.; Pakula, T.; Müllen, K. Adv. Mater. 2005, 17, 684-689. (i) Dimitrakopoulos, C. D.; Malenfant, P. R. L. Adv. Mater. 2002, 14, 99-117. (j) Schmidt-Mende, L.; Fechtenchötter, A.; Müllen, K.; Moons, E.; Friend, R. H.; MacKenzie, J. D. Science 2001, 293, 1119-1122. (k) Xiao, S.; Myers, M.; Miao, Q.; Sanaur, S.; Pang, K.; Steigerwald, M. L.; Nuckolls, C. Angew. Chem., Int. Ed. 2005, 44, 7390-7394.

(4) (a) Konishi, A.; Hirao, Y.; Nakano, M.; Shimizu, A.; Botek, E.; Champagne, B.; Shiomi, D.; Sato, K.; Takui, T.; Matsumoto, K.; Kurata, H.; Kubo, T. J. Am. Chem. Soc. 2010, 132, 11021-11023. (b) Fogel, Y.; Zhi, L.; Rouhanipour, A.; Andrienko, D.; Räder, H. J.; Müllen, K. Macromolecules 2009, 42, 6878-6884. (c) Feng, X.; Pisula, W.; Ai, M.; Gröper, S.; Rabe, J. P.; Müllen, K. Chem. Mater. 2008, 20, 1191-1193. (d) Feng, X.; Wu, J.; Ai, M.; Pisula, W.; Zhi, L.; Rabe, J. P.; Müllen, K. Angew. Chem., Int. Ed. 2007, 46, 3033-3036. (e) Okamoto, T.; Senatore, M. L.; Ling, M.-M.; Mallik, A. B.; Tang, M. L.; Bao, Z. Adv. Mater. 2007, 19, 3381-3384. (f) Terasawa, N.; Monobe, H.; Kiyohara, K.; Shimizu, Y. Chem. Lett. 2003, 32, 214-215. (g) Lee, M.; Kim, J.-W.; Peleshanko, S.; Larson, K.; Yoo, Y.-S.; Vaknin, D.; Markutsya, S.; Tsukruk, V. V. J. Am. Chem. Soc. 2002, 124, 91219128. (h) Yatabe, T.; Harbison, M. A.; Brand, J. D.; Wagner, M.; Müllen, K.; Samori, P.; Rabe, J. P. J. Mater. Chem. 2000, 10, 15191525. (i) Henderson, P.; Ringsdorf, H.; Schuhmacher, P. Liq. Cryst. 1995, 18, 191-195.

(5) (a) Feng, X.; Pisula, W.; Takase, M.; Dou, X.; Enkelmann, V.; Wagner, M.; Ding, N.; Müllen, K. Chem. Mater. 2008, 20, 2872-2874. (b) Chen, C.-W.; Chang, H.-Y.; Lee, S.-L.; Hsu, I.-J.; Lee, J.-J.; Chen, C.-h.; Luh, T.-Y. Macromolecules 2010, 43, 8741-8746.

(6) (a) Fujiyama, T.; Toya, Y.; Nakatsuka, M. Japanese Patent JP 2008098357, 2008. (b) Nakatsuka, M.; Shimamura, T.; Ishida, T.; Totani, Y. Japanese Patent JP 2002359081, 2002.

(7) Dötz, F.; Brand, J. D.; Ito, S.; Gherghel, L.; Müllen, K. J. Am. Chem. Soc. 2000, 122, 7707-7717.

(8) Alameddine, B.; Martin-Caba, S.; Schindler, M.; Jenny, T. A. Synthesis 2012, 44, 1928-1934.

(9) (a) Sato, T.; Tsuneda, T.; Hirao, K. J. Chem. Phys. 2007, 126, 234114. (b) Johnson, E. R.; Becke, A. D. J. Chem. Phys. 2006, 124, 174104. (c) Tsuzuki, S.; Honda, K.; Uchimaru, T.; Mikami, M. J. Chem. Phys. 2004, 120, 647-659.

(10) (a) von Lilienfeld, O. A.; Adrienko, D. J. Chem. Phys. 2006, 124, 054307. (b) Rapacioli, M.; Spiegelman, F.; Talbi, D.; Mineva, T.; Goursot, A.; Heine, T.; Seifert, G. J. Chem. Phys. 2009, 130, 244304. (c) Langreth, D. C.; Lundqvist, B. I.; Chakarova-Käck, S. D.; Cooper, V. R.; Dion, M.; Hyldgaard, P.; Kelkkanen, A.; Kleis, J.; Kong, L.; Li, S.; Moses, P. G.; Murray, E.; Puzder, A.; Rydberg, H.; Schröder, E.; Thonhauser, T. J. Phys.: Condens. Matter 2009, 21, 084203. (d) Hohenstein, E. G.; Sherrill, C. D. J. Chem. Phys. 2010, 132, 184111 .

(11) Marcon, V.; Vehoff, T.; Kirkpatrick, J.; Jeong, C.; Yoon, D. Y.; Kremer, K.; Andrienko, D. J. Chem. Phys. 2008, 129, 094505.

(12) (a) Ruiz-Morales, Y. J. Phys. Chem. A 2004, 108, 10873-10896. (b) Ruiz-Morales, Y. J. Phys. Chem. A 2002, 106, 11283-11308.

(13) Grimme, S. J. Comput. Chem. 2006, 27, 1787-1799.

(14) Grimme, S.; Antony, J.; Schwabe, T.; Mück-Lichtenfeld, C. Org. Biomol. Chem. 2007, 5, 741-758.

(15) (a) Grimme, S.; Antony, J.; Ehrlich, S.; Krieg, H. J. Chem. Phys. 2010, 132, 154104. (b) Grimme, S.; Ehrlich, S.; Goerigk, L. J. Comput. Chem. 2011, 32, 1456-1465.

(16) Becke, A. D. J. Chem. Phys. 1997, 107, 8554-8560.

(17) (a) Jurečka, P.; Šponer, J.; Černý, J.; Hobza, P. Phys. Chem. Chem. Phys. 2006, 8, 1985-1993. (b) Takatani, T.; Hohenstein, E. G.; Malagoli, M.; Marshall, M. S.; Sherrill, C. D. J. Chem. Phys. 2010, 132, 144104.

(18) Goerigk, L.; Grimme, S. Phys. Chem. Chem. Phys. 2011, 13, 6670-6688.

(19) Řezáč, J.; Riley, K. E.; Hobza, P. J. Chem. Theory Comput. 2011, 7, 2427-2438.

(20) Goerigk, L.; Kruse, H.; Grimme, S. Chem. Phys. Chem 2011, 12, $3421-3433$.

(21) Burns, L. A.; Vázquez-Mayagoita, Á.; Sumpter, B. G.; Sherrill, C. D. J. Chem. Phys. 2011, 134, 084107.

(22) Antony, J.; Grimme, S.; Liakos, D. G.; Neese, F. J. Phys. Chem. A 2011, 115, 11210-11220. 
(23) (a) Waller, M. P.; Kruse, H.; Mück-Lichtenfeld, C.; Grimme, S. Chem. Soc. Rev. 2012, 41, 3119-3128. (b) Antony, J.; Grimme, S. J. Comput. Chem. 2012, 33, 1730-1739.

(24) (a) Schäfer, A.; Huber, C.; Ahlrichs, R. J. Chem. Phys. 1994, 100, 5829-5835. (b) Weigend, F.; Furche, F.; Ahlrichs, R. J. Chem. Phys. 2003, 119, 12753-12762.

(25) (a) Eichkorn, K.; Treutler, O.; Öhm, H.; Häser, M.; Ahlrichs, R. Chem. Phys. Lett. 1995, 240, 283-290. (b) Eichkorn, K.; Treutler, O.; Öhm, H.; Häser, M.; Ahlrichs, R. Chem. Phys. Lett. 1995, 242, 652660.

(26) Turbomole Version 5.9: Program Package for ab Initio Electronic Structure Calculations; COSMOlogic $\mathrm{GmbH} \&$ Co. KG: Leverkusen, Germany, 2008.

(27) The basis sets are available from the Turbomole homepage through the FTP Server Button: http://www.cosmologic.de/ QuantumChemistry/ftpServer.html (accessed June 2009).

(28) Boys, S. F.; Bernardi, F. Mol. Phys. 1970, 19, 553-566.

(29) Tao, J.; Perdew, J. P.; Staroverov, V. N.; Scuseria, G. E. Phys. Rev. Lett. 2003, 91, 146401-146404. 